\title{
Hydrolytic denitrification and decynidation of acrylonitrile in wastewater with Arthrobacter nitroguajacolicus ZJUTB06-99
}

\author{
Yaping Guo ${ }^{1 *} \mathbb{D}$, Hui Chang ${ }^{1}$, Qiaoling Wang ${ }^{1}$, Chenjia Shao ${ }^{1}$ and Jianmiao Xu
}

\begin{abstract}
Acrylonitrile $\left(\mathrm{C}_{3} \mathrm{H}_{3} \mathrm{~N}\right)$ widely used in chemical raw materials has biological toxicity with - $\mathrm{CN}$ bond, so it is the key to removal of cyanide from acrylonitrile wastewater. In our previous research and investigation, a strain was identified as Arthrobacter nitroguajacolicus named ZJUTB06-99 and was proved to be capable of degrading acrylonitrile. In this paper, the strain ZJUTB06-99 was domesticated with acrylonitrile-containing medium and its decyanidation and denitrification in simulated acrylonitrile wastewater were studied. The intermediate product of acrylonitrile in degradation process was identified through gas chromatography-mass spectrometer, as well as the biodegradation pathway of acrylonitrile in wastewater was deduced tentatively. The kinetics equation of biodegradation of acrylonitrile was $\ln C=-0.1784 t+5.3349$, with the degradation half-life of acrylonitrile in wastewater by $3.885 \mathrm{~h}$. The results of this study showed that the optimum levels of temperature, $\mathrm{pH}$ and bacteria concentration to attain the maximum biodegradation were obtained as $30^{\circ} \mathrm{C}, 6$ and $100 \mathrm{~g} / \mathrm{L}$, respectively. The disadvantages of the biodegradation with this strain and its possible enhanced method to degrade acrylonitrile in wastewater were also discussed.
\end{abstract}

Keywords: Acrylonitrile, Hydrolytic, Denitrification, Decyanidation, Biotreatment, Wastewater

\section{Introduction}

Acrylonitrile is a kind of highly poisonous organic compound bearing a $-\mathrm{CN}$ group that is extensively used in synthesis of rubbers, acrylic fibers, plastics and other synthetic materials (Baxter et al. 2006; Ramteke et al. 2013). Besides, acrylonitrile is third of the 129 priority pollutants listed by EPA (Keith and Telliard 1979; Kumar et al. 2008). The global production of acrylonitrile exceeds 5 million tons, with a proportion of $28 \%$ produced in China (Dong et al. 2017; Zheng et al. 2015). Thus, a large amount of acrylonitrile wastewater is generated during the production (Lai et al. 2012), which has inevitably caused serious impact on public and environmental health (Ramteke et al. 2013). Furthermore, these emerging pollution sources are highly toxic, carcinogenic (Ramakrishna et al. 1989; Thier et al. 2000; Quast

\footnotetext{
*Correspondence: luckyyaping@163.com

${ }^{1}$ College of Environment, Zhejiang University of Technology,

Hangzhou 310014, People's Republic of China

Full list of author information is available at the end of the article
}

2002) and related toxicity investigation has been widely reported, e.g. acrylonitrile could leads to neurobehavioral disorder in rats and some human sicknesses (Caito et al. 2013; Khan et al. 2009; Tanii and Hashimoto 1984). So it is urgent to explore safe and efficient treatment technology on acrylonitrile wastewater treatment.

In the past few years, there are a large number of treatment methods have been developed to degrade acrylonitrile wastewater, including Fenton oxidation (Popuri et al. 2011), supercritical water oxidation (Shin et al. 2009), radiation (Abdel-Aal et al. 2006) and wet air oxidation (Mishra et al. 1995). At present, the biodegradation of acrylonitrile in wastewater is considered to be one of the major routes due to its simple management and high efficiency (Wyatt and Knowles 1995; Kubsad et al. 2011; Santoshkumar et al. 2011). For example, an acrylonitriledegrading bacterial strain was isolated from the activated sludge of petrochemical wastewater treatment system to investigate its efficiency in acrylonitrile removal (Shakerkhatibi et al. 2010). A novel nitrilase-producing of Streptomyces sp. MTCC 7546, was immobilized in 
agar powder to discuss these cells on biotransformation of acrylonitrile, and the results indicated that the bacteria could efficiently be used for the bioconversion of acrylonitrile to acids without producing amides (Agarwal and Nigam 2017; Nigam et al. 2009). Rhodococcus rhodochrous $\mathrm{BX} 2$ was possessing the expression of corresponding metabolic enzymes to degrade acrylonitrile completely (Santoshkumar et al. 2011). A newly strain named Rhodococcus ruber AKSH-84 was screened from a petroleum-contaminated sludge sample and it has proved to be able to be used in green biosynthesis of acrylic acid for biotechnological processes (Kamal et al. 2011). In a previous research, Arthrobacter nitroguajacolicus ZJUTB06-99, capable of converting acrylonitrile to acrylic acid, was isolated in our laboratory (Shen et al. 2009a). Moreover, it was focused on study the biotransformation of acrylonitrile into acrylic acid by using nitrile-converting enzymes as biocatalysts and investigated the optimal medium components of nitrilase production (Shen et al. 2010; Shen et al. 2009b).

In this work, high concentration of the strain of ZJUTB06-99 was induced in the simulated acrylonitrile wastewater and was centrifuged. Then, it was used in simulated acrylonitrile wastewater to investigate its possibility of decyanidation and denitrification. The possible biodegradation pathway of acrylonitrile and kinetics equation were discussed, separately. Furthermore, the biodegradation effects of acrylonitrile wastewater and their influencing factors were also exhibited. Finally, it was revealed the disadvantages of biodegradation with this strain and discovered the possible enhanced method to degrade acrylonitrile in wastewater, which was contributed to further exploration of practical application in acrylonitrile wastewater.

\section{Materials and methods}

\section{Materials and medium}

Acrylonitrile used in this study was obtained from Aladdin Industrial Inc. (Shanghai, China). All other chemicals were of analytical grade. Glassware was meticulously cleaned to reduce any background contamination.

LB medium for enrichment with the following composition was used: $1.0 \mathrm{~L}$ deionized water, $10.0 \mathrm{~g}$ glucose, 5.0 g yeast extract, $0.5 \mathrm{~g} \mathrm{KH}_{2} \mathrm{PO}_{4}, 0.5 \mathrm{~g} \mathrm{~K}_{2} \mathrm{HPO}_{4}, 0.5 \mathrm{~g}$ $\mathrm{MgSO}_{4} \cdot 7 \mathrm{H}_{2} \mathrm{O}$.

The solid medium of LB for isolation contained 1.0 L deionized water, $10.0 \mathrm{~g}$ peptone, $5.0 \mathrm{~g}$ beef paste, $5.0 \mathrm{~g}$ $\mathrm{NaCl}, 20 \mathrm{~g}$ agar.

The $\mathrm{pH}$ values of all media were adjusted to $7.2 \pm 0.2$ with $\mathrm{NaOH}(1 \mathrm{~mol} / \mathrm{L})$, and media were sterilized by autoclaving at $121^{\circ} \mathrm{C}$ for $20 \mathrm{~min}$.

\section{Bacteria growth}

ZJUTB06-99 has been deposited in the China Center for Type Culture Collection under accession number CCTCCM208252.

The media used for isolation of Arthrobacter nitroguajacolicus from contaminated soil, preservation of the isolated acrylonitrile-degrading strains, was prepared as follows. In this research approach, this strain was cultured on plate medium containing acrylonitrile $(200 \mathrm{mg} / \mathrm{L})$ prepared as mentioned above. Approximately $3 \%$ of the inocula of the seed medium were inoculated into $250 \mathrm{~mL}$ flasks with $50 \mathrm{~mL}$ of culture medium and then cultured at $30{ }^{\circ} \mathrm{C}$ for $24 \mathrm{~h}$. The strain were harvested by centrifugation $(10,000 \mathrm{r} / \mathrm{min}$, $10 \mathrm{~min}$ ) and washed with deionized water for three times, which was maintained in $15 \%$ glycerol solution at $-80{ }^{\circ} \mathrm{C}$ for further use. As shown in Fig. 1, the pure colony of ZJUTB06-99 was characterized by a round shape, light milky yellow, neat and smooth edge.

\section{Optimal experiments}

To determine optimal conditions for degrading acrylonitrile by the strain ZJUTB06-99, single-factor optimization tests were designed in this study under different growth conditions including $\mathrm{pH}(5,6,7,8,9)$, temperature $\left(25,30,35,40{ }^{\circ} \mathrm{C}\right)$, bacteria concentration $(20,30,40,50,75,100 \mathrm{mg} / \mathrm{L})$. The initial acrylonitrile concentration was maintained at $200 \mathrm{mg} / \mathrm{L}$. The residual concentration of acrylonitrile was determined by GC.

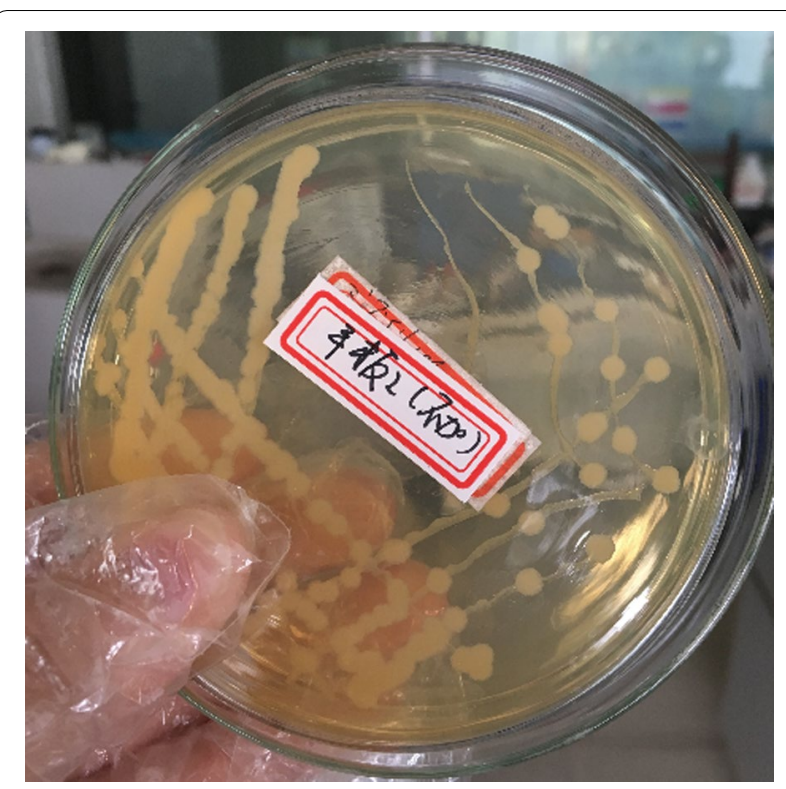

Fig. 1 The colony of ZJUTB06-99 on plate 


\section{Analytical methods}

Reaction sample was collected directly from the reactor with a syringe and passed through a $0.22 \mu \mathrm{m}$ membrane filter to remove the bacteria. The concentration of acrylonitrile was determined by gas chromatograph (Agilent $6890 \mathrm{~N}$, USA) equipped with an automatic injector and a flame ionization detector (FID). The experimental conditions were as follows: the injection temperature was set at $160{ }^{\circ} \mathrm{C}$; and the column and detector temperatures were set at $170{ }^{\circ} \mathrm{C}$ and $200{ }^{\circ} \mathrm{C}$, respectively. The intermediate product in the degradation process was analyzed by GC-MS (Agilent 7890/5975, USA), equipped with a HP-5MS capillary column. The GC column was operated in temperature programmed mode at $40{ }^{\circ} \mathrm{C}$ for $1 \mathrm{~min}$, raised to $80{ }^{\circ} \mathrm{C}$ at a rate of $10{ }^{\circ} \mathrm{C} / \mathrm{min}$, and then raised at $210^{\circ} \mathrm{C}$ (held for $3 \mathrm{~min}$ ).

The concentrations of nitrite, nitrate and total nitrogen, ammonia in water samples were assayed according to Chinese Standard Methods. The $\mathrm{pH}$ value of the solution was determined with a $\mathrm{pH}$ meter. The content of dissolved oxygen was detected by micro-breathing electrode (Unisense, Denmark).

\section{Reactor system}

The reactor was made of transparent synthetic glass container of $40 \mathrm{~mm}$ in length and $40 \mathrm{~mm}$ in width and $150 \mathrm{~mm}$ in height. Simulative acrylonitrile wastewater with the volume of $200 \mathrm{~mL}$ and ZJUTB06-99 were mixed together in a glass container, then put the reactor on a digital thermostat magnetic stirrer with temperature probe. The structure of the reaction apparatus was shown in Fig. 2.

\section{Results}

\section{Biodegradation pathway of acrylonitrile}

In order to understand the biodegradation process of acrylonitrile, the intermediate product during the experiment were tentatively detected by GC-MS. Total ion chromatogram and mass spectrograms were exhibited in Figs. 7, 8, and 9, respectively.

There were two peaks with relatively larger response values marked as Peak I and Peak II, as shown in Fig. 3, whose retention time were $12.65 \mathrm{~min}$ and $17.35 \mathrm{~min}$ respectively.

After searching in the reference mass spectral library, the highest matched mass spectrogram was retrieved according to the peaks in total ion current chromatogram. Peak I was acrylonitrile shown as Fig. 4a and Peak II was acrylic acid shown as Fig. 4b. It can be known that acrylic acid was the main intermediate product during the course of biodegradation.

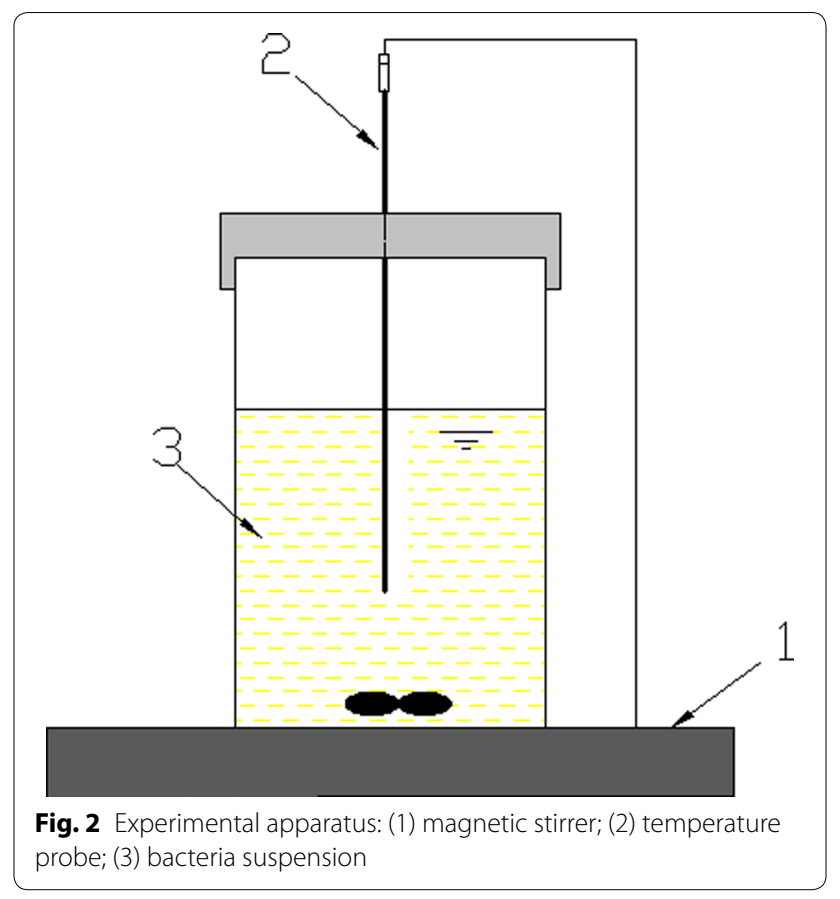

The concentration of acrylonitrile and acrylic acid in the water samples were detected by GC. The degradation amount of acrylonitrile and production amount of acrylic acid were shown in Table 1.

ZJUTB06-99 could degrade acrylonitrile to acrylic acid and the molar ratio of acrylonitrile's degradation to acrylic acid's yield was close to 1:1 (Table 1). Besides, it was detected that the content of total nitrogen in the solution was reduced slightly, which was indicated that the ZJUTB06-99 has favorable impact on the removal of $-\mathrm{CN}$ bond so as to reduce the toxicity of acrylonitrile. Combining the above results and the previous research on biotransformation reaction of acrylonitrile, it was speculated that the biodegradation process of acrylonitrile wastewater by ZJUTB06-99 conforms to hydrolysis reaction shown as follows:

$$
\mathrm{CH}_{2}=\mathrm{CH}-\mathrm{C} \equiv \mathrm{N}+\mathrm{H}_{2} \mathrm{O} \stackrel{\mathrm{Z} \text { ZJUTB06-99 }}{\longrightarrow} \mathrm{CH}_{2}=\mathrm{CH}-\mathrm{C}-\mathrm{OH}+\mathrm{NH}_{3}
$$

\section{Degradation kinetics}

In order to degrade acrylonitrile wastewater with the concentration of $200 \mathrm{mg} / \mathrm{L}$, the experiment was carried out for $8 \mathrm{~h}$ and the following degradation curve was shown in Fig. 5. Here, the Y-axis represented to the natural logarithm of acrylonitrile concentration $(\ln C)$ and the $\mathrm{X}$-axis represented to reaction time $(\mathrm{t})$. The kinetics equation was $\ln C=-0.1784 \mathrm{t}+5.3349$ with the coefficient of determination $\mathrm{R}^{2}$ was determined 


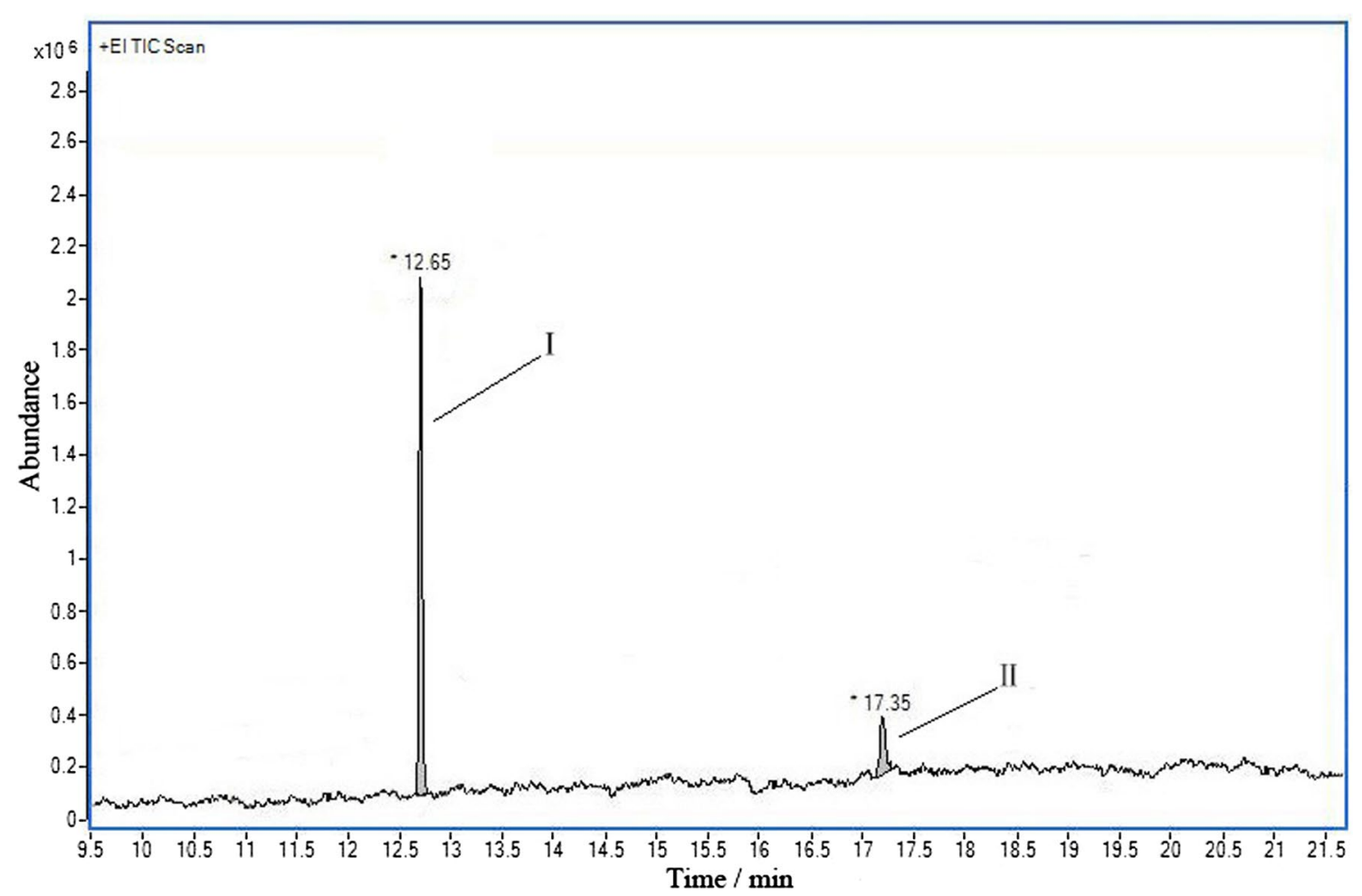

Fig. 3 Total ion current chromatogram

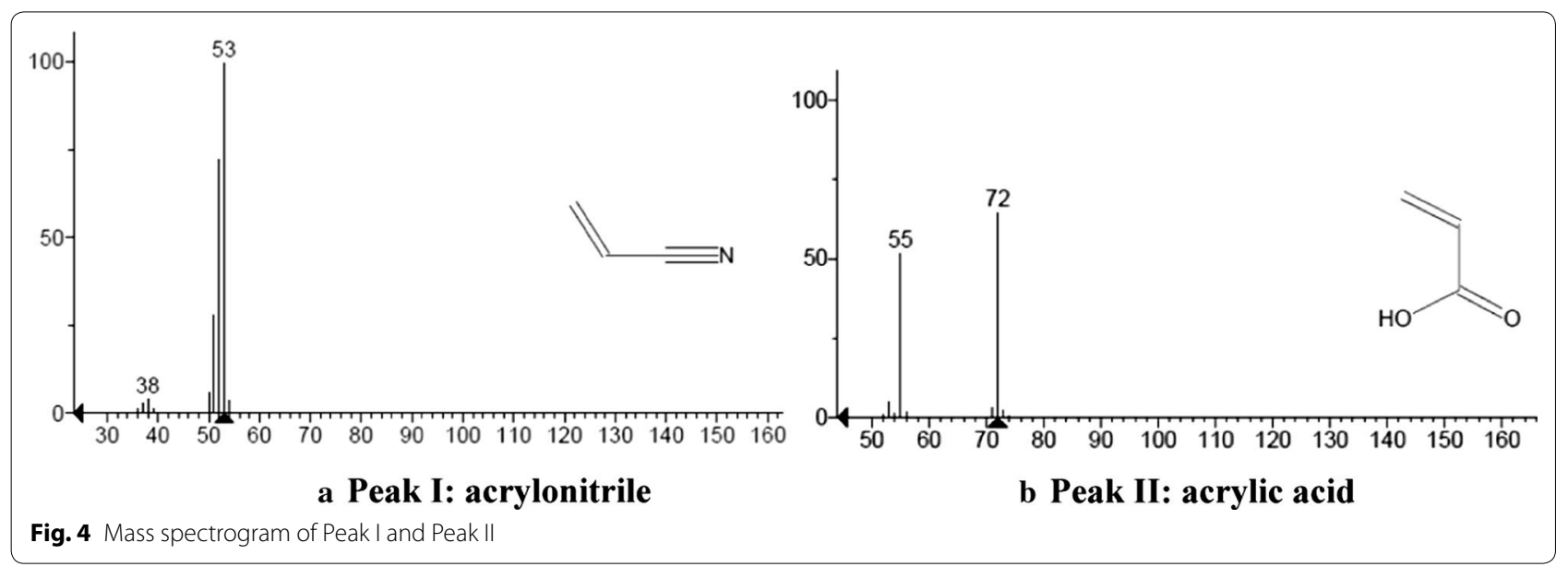

Table 1 The degradation amount of acrylonitrile and the production amount of acrylic acid

\begin{tabular}{lll}
\hline $\begin{array}{l}\text { Reaction } \\
\text { time/(h) }\end{array}$ & $\begin{array}{l}\text { The degradation amount } \\
\text { of acrylonitrile/(mmol) }\end{array}$ & $\begin{array}{l}\text { The production amount } \\
\text { of acrylic acid/(mmol) }\end{array}$ \\
\hline 8 & 0.6163 & 0.5939 \\
\hline
\end{tabular}

to be 0.994, suggesting that the experimental data was correlated well with the first order reaction kinetics model. Besides, the $\mathrm{k}$ (slope of line) and half-life $\left(\mathrm{t}_{1 / 2}\right)$ of ZJUTB06-99 was 0.1784 $\mathrm{h}^{-1}$ and $3.885 \mathrm{~h}$, respectively. 


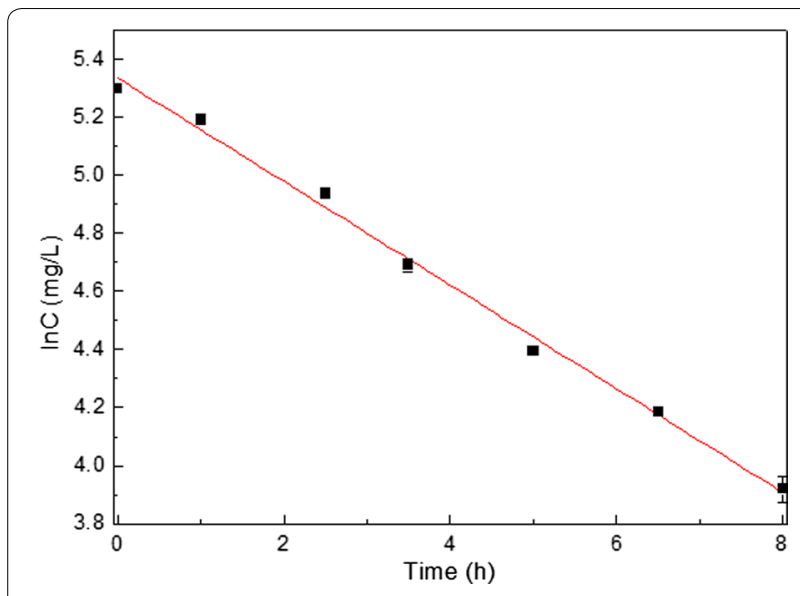

Fig. 5 Kinetic curve of degradation

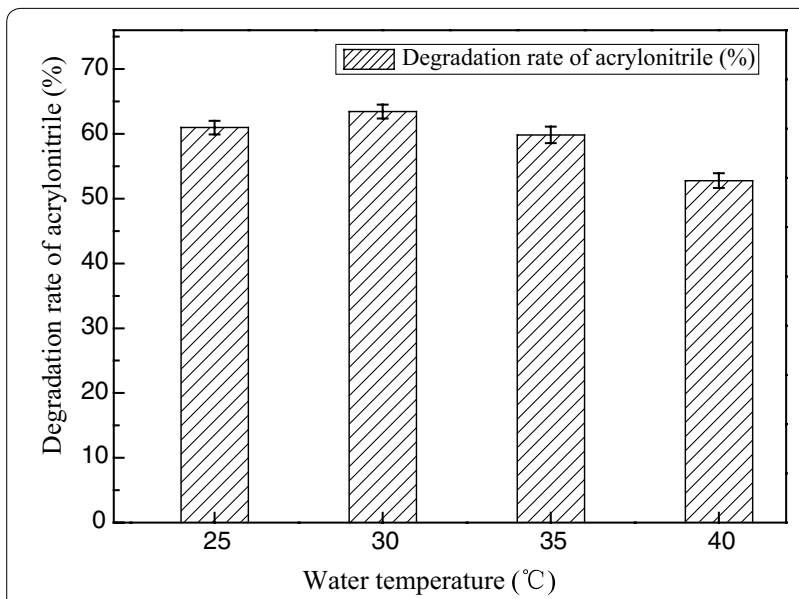

Fig. 6 Influence of temperature on acrylonitrile biodegradation rate. The degradation rate increased with the increase of temperature between 25 and $30^{\circ} \mathrm{C}$. A high rate was achieved for ZJUTB06-99 when the temperature was $30^{\circ} \mathrm{C}$

Influence of temperature on acrylonitrile biodegradation Four different temperatures $\left(25,30,35,40{ }^{\circ} \mathrm{C}\right)$ were thus used to examine the effect of temperature on the biodegradation of acrylonitrile by ZJUTB06-99. As indicated in Fig. 6, the degradation rate increased with the increasing of temperature between 25 and $30{ }^{\circ} \mathrm{C}$. This effect was very pronounced when temperature was varied from 25 to $40{ }^{\circ} \mathrm{C}$. Too high or too low temperature was unfavorable for acrylonitrile degradation.

\section{Influence of $\mathrm{pH}$ on acrylonitrile biodegradation}

The effect of $\mathrm{pH}$ ranging from 5 to 9 on the degradation of acrylonitrile was shown in Fig. 7. It was implied that the rate of acrylonitrile degradation increased when the

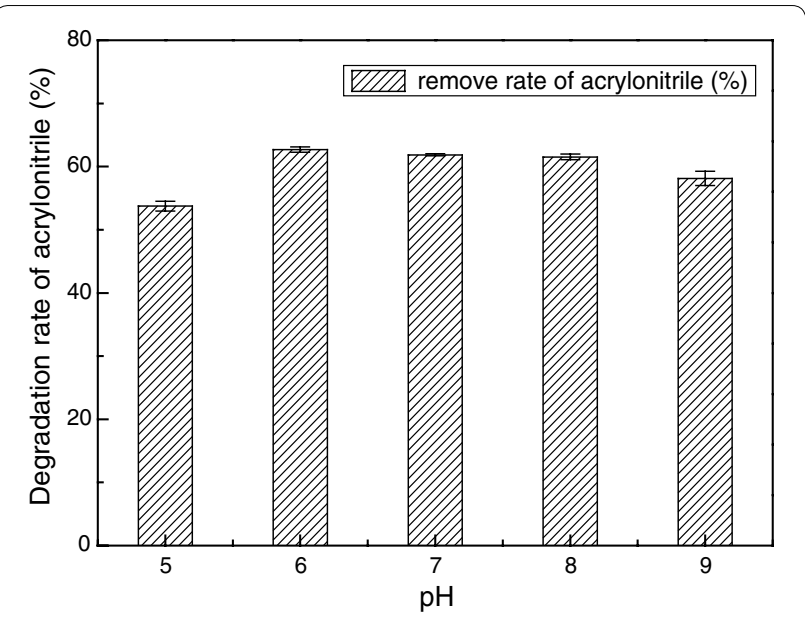

Fig. 7 Influence of $\mathrm{pH}$ on acrylonitrile biodegradation rate. The rate of acrylonitrile degradation increased when the $\mathrm{pH}$ value was increased from 5 to 6 . The optimal pH values for ZJUTB06-99 to degrade acrylonitrile were from 6 to 8

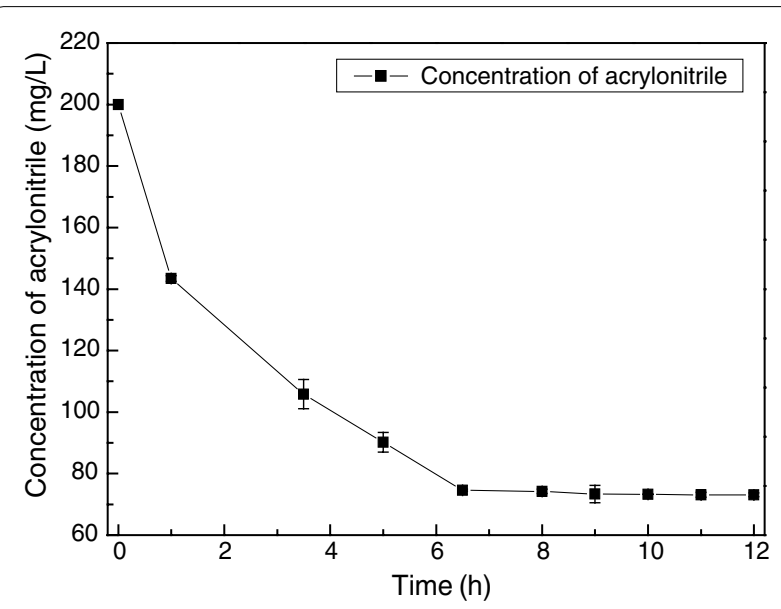

Fig. 8 Influence of reaction time on acrylonitrile biodegradation rate. The concentration of acrylonitrile was constantly decreasing with the increase of time. After $8 \mathrm{~h}$, the residual of acrylonitrile decreased slowly and gradually became stable. The optimum biodegradation time was determined to be $8 \mathrm{~h}$

$\mathrm{pH}$ value was increased from 5 to 6 . The optimal $\mathrm{pH}$ values for ZJUTB06-99 to degrade acrylonitrile was 6 . The degradation rates from 6 to 8 were higher probably because some key enzymes responsible for acrylonitrile degradation possessed good tolerance at this range of $\mathrm{pH}$.

\section{Influence of reaction time}

It has been carried out for $12 \mathrm{~h}$ during the biodegradation process to investigate the optimal reaction time. As it could be seen from the results in Fig. 8, the concentration 


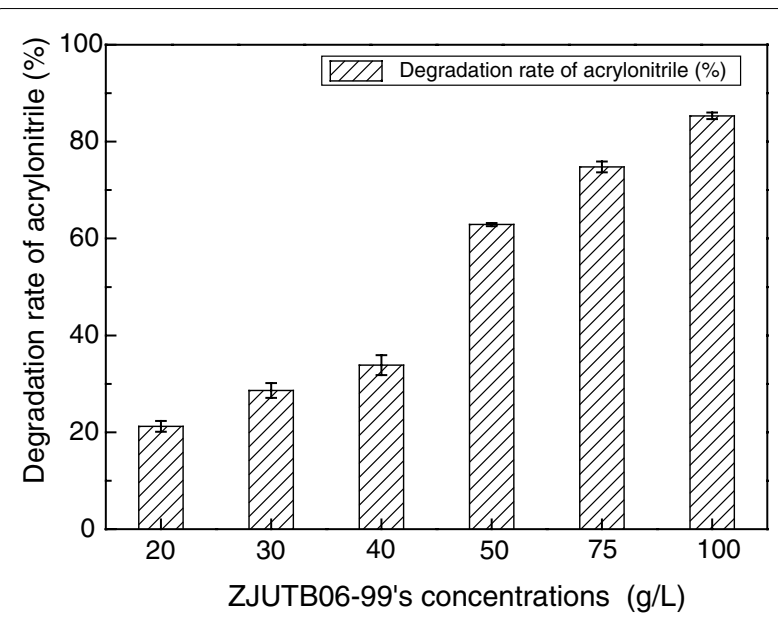

Fig. 9 Influence of ZJUTB06-99's concentration on the biodegradation. The effect of ZJUTB06-99's concentration on the acrylonitrile's biodegradation rate. The factor of ZJUTB06-99's concentration showed the strongest influence on the response when it varied in the range of 20 to $100 \mathrm{mg} / \mathrm{L}$. Especially, the degradation rate of acrylonitrile reached to $85.3 \%$ with the ZJUTB06-99's concentration of $100 \mathrm{~g} / \mathrm{L}$. The results could be justified by the higher amounts of effective enzymes that were produced as the concentration of ZJUTB06-99 were increased

of acrylonitrile was constantly decreasing with the increasing of time. After $8 \mathrm{~h}$, the residual of acrylonitrile decreased slowly and gradually became stable. So the optimum biodegradation time was determined to be $8 \mathrm{~h}$.

\section{Influence of ZJUTB06-99's concentration}

The optimization biodegradation on acrylonitrile under different ZJUTB06-99's concentration was investigated. Figure 9 indicated that the effect of ZJUTB06-99's concentration on the acrylonitrile's biodegradation rate. The factor of bacteria concentration showed the strongest influence on the response when it varied in the range of 20-100 $\mathrm{mg} / \mathrm{L}$. Especially, the degradation rate of acrylonitrile reached to $85.3 \%$ with the ZJUTB06-99's concentration of $100 \mathrm{~g} / \mathrm{L}$. The results could be justified by the higher amounts of effective enzymes that were produced as the concentration of ZJUTB06-99 were increased.

\section{Discussion}

With a growing awareness of the detrimental effects of acrylonitrile on the human and environment health, and its importance in synthetic raw materials, researchers pay great attention to the methods on acrylonitrile biological degradation. It is well known that many microorganisms could use acrylonitrile as carbon or nitrogen sources (Asano et al. 1981) and the main metabolic pathways are converted acrylonitrile to amides by nitrile hydratase (Hughes et al. 1998; Santoshkumar et al. 2017) and to carboxylic acids by nitrilase or by a combination of nitrile hydratase (Bandyopadhyay et al. 1986; Kato et al. 1998).

In this paper, the strain named ZJUTB06-99 was harvested to study its decyanidation and denitrification in simulated acrylonitrile wastewater. This result revealed the investigation of intermediate product and the probably metabolic pathway by ZJUTB06-99 in acrylonitrile wastewater. According to the analysis of GC-MS, the supposed degradation pathway of acrylonitrile by strain ZJUTB06-99 was shown above. The processes could be deduced that acrylonitrile was hydrolyzed to acrylic acid and $\mathrm{NH}_{3}$ with the breakdown of $-\mathrm{CN}$ bond, indicated that the strain ZJUTB06-99 has better effect on decyanidation to reduce the toxicity of acrylonitrile in wastewater. Figure 5 showed the degradation kinetic equation at acrylonitrile initial concentration of $200 \mathrm{mg} / \mathrm{L}$. Analyzed by Origin 8.0 , the degradation kinetics equation in acrylonitrile wastewater by ZJUTB06-99 was $\ln C=-0.1784 t+5.3349$, and the degradation rate was $0.1784 \mathrm{~h}^{-1}$. The result demonstrated that biodegradation reaction fit with the first-order kinetics.

Previous studies revealed that the effect of factors on pollutants degradation by microorganisms were always sensitive to $\mathrm{pH}$ and temperature (Wang et al. 2011; Kaira et al. 2015). Environmental pH could determine the biodegradation efficiency by affecting microbial diversity and enzyme's activity (Antoniou et al. 1990; Lin et al. 2010). For example, The Bacillus pallidus strain Dac521 containing nitrilase was induced in the thermophilic bacterium, and the enzymatic activity was found to have a constant between $\mathrm{pH} 6$ and 9, with an optimum lever at pH 7.6 (Almatawah et al. 1999). Temperature influences biological life mainly by affecting the activity of biological enzyme and the mobility of microbial cell membrane (Taniguchi et al. 2017; Huang et al. 2018; Mehak et al. 2016). As the temperature gradually increases, the rate of intracellular enzymatic reactions increases. However, once the temperature exceeds the range that the organism can tolerate, the activity of the organism will decrease and even cause death (Kunze et al. 2014).

In accordance with this, strain ZJUTB06-99 showed high degradation efficiency under a wide range of $\mathrm{pH}$ 6-8. Particularly, the degradation rate of acrylonitrile was $62.69 \%$ under $\mathrm{pH}$ 6. A high rate was achieved for ZJUTB06-99 when the temperature was $30{ }^{\circ} \mathrm{C}$, which was a litter different from the previous study (Shen et al. 2009b). The optimum for temperature, biodegradation time, and concentration of ZJUTB06-99 were obtained at $30^{\circ} \mathrm{C}, 8 \mathrm{~h}$, and $100 \mathrm{mg} / \mathrm{L}$, respectively.

This work has demonstrated that biology method is cost-effective to treat acrylonitrile wastewater by utilizing ZJUTB06-99, while there still exists some disadvantages in this biodegradation process with strain 
ZJUTB06-99. It was found that the product of acrylic acid was still not easily biodegradable and the concentration of TN decreased slightly after this degradation. Thus, it is necessary to find a method to degrade acrylonitrile efficiently and decrease the concentration of $\mathrm{TN}$ more thoroughly in acrylonitrile wastewater. Based on this work of ZJUTB06-99, our team has studied a coupling technology with electrical catalytic enzyme to enhance the degradation and denitrification of acrylonitrile in wastewater, which hope to be published in this journal later.

\section{Abbreviations}

GC-MS: gas chromatography-mass spectrometer; GC: gas chromatography; EPA: Environmental Protection Agency.

\section{Authors' contributions}

$\mathrm{HC}$ and QLW participated in the experiments. HC designed the experiments and wrote the manuscript. CJS analyzed the data. YPG was responsible for initiation and supervision of the study. YPG and JMX participated in the study design and provided critical review of the manuscript. All authors read and approved the final manuscript.

\section{Author details}

${ }^{1}$ College of Environment, Zhejiang University of Technology, Hangzhou 310014, People's Republic of China. ${ }^{2}$ College of Biotechnology and Bioengineering, Zhejiang University of Technology, Hangzhou 310014, People's Republic of China.

\section{Acknowledgements}

The author thanks to Professor Yuguo Zheng for his assistance in biology technology and research advice.

\section{Competing interests}

The authors declare that they have no competing interests.

\section{Availability of data and materials}

The data supporting the conclusions are presented in the main article.

\section{Consent for publication}

Not applicable.

\section{Ethics approval and consent to participate}

Not applicable. This paper does not contain any studies with human participants or animal performed by any of the authors.

\section{Funding}

The authors gratefully acknowledge financial support from National Natural Science Foundation of China (No. 51108416) and the Key Project of Science and Technology of Zhejiang Province (No. 2011C14023).

\section{Publisher's Note}

Springer Nature remains neutral with regard to jurisdictional claims in published maps and institutional affiliations.

Received: 26 September 2018 Accepted: 21 November 2018

Published online: 03 December 2018

\section{References}

Abdel-Aal SE, Gad YH, Dessouki AM (2006) Use of rice straw and radiationmodified maize starch/acrylonitrile in the treatment of wastewater. J Hazard Mater 129(1):204-215. https://doi.org/10.1016/j.jhazmat.2005.08.041
Agarwal A, Nigam VK (2017) Enhanced production of nitrilase from Streptomyces sp. MTCC 7546 by response surface method. Proc Natl Acad Sci India Sect B Biol Sci 87(2):603-609. https://doi.org/10.1007/s40011-015-0638-2

Almatawah QA, Cramp R, Cowan DA (1999) Characterization of an inducible nitrilase from a thermophilic bacillus. Extremophiles 3(4):283-291. https:// doi.org/10.1007/s007920050129

Antoniou P, Hamilton J, Koopman B, Jain R, Holloway B, Lyberatos G, Svoronos SA (1990) Effect of temperature and $\mathrm{pH}$ on the effective maximum specific growth rate of nitrifying bacteria. Water Res 24(1):97-101. https:// doi.org/10.1016/0043-1354(90)90070-M

Asano Y, Ando S, Tani Y, Yamada H, Ueno T (1981) Fungal degradation of triacrylonitrile. Agric Biol Chem 45(1):57-62

Bandyopadhyay AK, Nagasawa T, Asano Y, Fujishiro K, Tani Y, Yamada H (1986) Purification and characterization of benzonitrilases from Arthrobacter sp. strain J-1. Appl Environ Microbiol 51(2):302-306

Baxter J, Garton NJ, Cummings SP (2006) The impact of acrylonitrile and bioaugmentation on the biodegradation activity and bacterial community structure of a topsoil. Folia Microbiol 51(6):591-597. https://doi. org/10.1007/BF02931624

Caito S, Yu YC, Aschner M (2013) Differential response to acrylonitrile toxicity in rat primary astrocytes and microglia. Neurotoxicology 37(3):93-99. https ://doi.org/10.1016/j.neuro.2013.04.007

Dong HH, Wang W, Song ZZ, Dong H, Wang JF, Sun SS, Zhang ZZ, Ke M, Zhang ZJ, Wu WM, Zhang GQ, Ma J (2017) A high-efficiency denitrification bioreactor for the treatment of acrylonitrile wastewater using waterborne polyurethane immobilized activated sludge. Bioresour Technol 239:472-481. https://doi.org/10.1016/j.biortech.2017.05.015

Huang JF, Ou YX, Zhang DF, Zhang GG, Pan YT (2018) Optimization of the culture condition of Bacillus mucilaginous using Agaricus bisporus industrial wastewater by Plackett-Burman combined with Box-Behnken response surface method. AMB Express 8(1):141. https://doi.org/10.1186/s1356 8-018-0671-7

Hughes J, Armitage YC, Symes KC (1998) Application of whole cell R. rhodococcal biocatalysts in acrylic polymer manufacture. Antonie Van Leeuwenhoek 74:107-118. https://doi.org/10.1023/A:1001716332272

Kaira GS, Dhakar K, Pandey A (2015) A psychrotolerant strain of Serratia marcescens (MTCC 4822) produces laccase at wide temperature and $\mathrm{pH}$ range. AMB Express 5(1):1. https://doi.org/10.1186/s13568-014-0092-1

Kamal A, Kumar MS, Kumar CG, Shaik T (2011) Bioconversion of acrylonitrile to acrylic acid by Rhodococcus ruber strain AKSH-84. J Microbiol Biotechnol 21(1):37-42

Kato Y, Ooi R, Asano Y (1998) Isolation and characterization of a bacterium possessing a novel aldoxime-dehydration activity and nitrile-degrading enzymes. Arch Microbiol 170(2):85-90

Keith LH, Telliard WA (1979) Priority pollutants. I. A perspective view. Environ Sci Technol 13(4):416-423

Khan HA, Alhomida AS, Arif IA (2009) On the mechanism of nitriles toxicity. Toxicol Sci 110(1):246-248

Kubsad V, Gupta SK, Chaudhari S (2011) Biodegradation of wastewater containing cyanide, acetonitrile, and acrylonitrile using RBC and shock loading study. Can J Chem Eng 89(6):1536-1544

Kumar A, Prasad B, Mishra IM (2008) Optimization of process parameters for acrylonitrile removal by a low-cost adsorbent using Box-Behnken design. J Hazard Mater 150(1):174-182. https://doi.org/10.1016/j.jhazm at.2007.09.043

Kunze M, Lattermann C, Diederichs S, Kroutil W, Büchs J (2014) Minireactorbased high-throughput temperature profiling for the optimization of microbial and enzymatic processes. J Biol Eng 8(1):22. https://doi. org/10.1186/1754-1611-8-22

Lai B, Zhou Y, Yang P, Wang K (2012) Comprehensive analysis of the toxic and refractory pollutants in acrylonitrile-butadiene-styrene resin manufacturing wastewater by gas chromatography spectrometry with a mass or flame ionization detector. J Chromatogr A 1244:161-167. https://doi. org/10.1016/j.chroma.2012.04.058

Lin C, Gan L, Chen ZL (2010) Biodegradation of naphthalene by strain Bacillus fusiformis (BFN). J Hazard Mater 182(1):771-777. https://doi.org/10.1016/j. jhazmat.2010.06.101

Mehak B, Lata N, Yutaka K, Pratyoosh S (2016) Current technological improvements in enzymes toward their biotechnological applications. Front Microbiol 7:965 
Mishra VS, Mahajani WV, Joshi JB (1995) Wet air oxidation. Ind Eng Chem Res 34(1):2-48

Nigam VK, Khandelwal AK, Gothwal RK, Mohan MK, Choudhury B, Vidyarthi AS, Ghosh P (2009) Nitrilase-catalysed conversion of acrylonitrile by free and immobilized cells of Streptomyces sp. J Biosci 34(1):21-26. https://doi. org/10.1007/s12038-009-0005-7

Popuri SR, Chang CY, Xu J (2011) A study on different addition approach of Fenton's reagent for DCOD removal from ABS wastewater. Desalination 277(1):141-146. https://doi.org/10.1016/j.desal.2011.04.017

Quast JF (2002) Two-year toxicity and oncogenicity study with acrylonitrile incorporated in the drinking water of rats. Toxicol Lett 132(3):153-196. https://doi.org/10.1016/S0378-4274(02)00072-3

Ramakrishna C, Kar D, Desai JD (1989) Biotreatment of acrylonitrile plant effluent by powdered activated carbon-activated sludge process. J Ferment Bioeng 67(6):430-432. https://doi.org/10.1016/0922-338X(89)90152-9

Ramteke PW, Maurice NG, Joseph B, Wadher BJ (2013) Nitrile-converting enzymes: an eco-friendly tool for industrial biocatalysis. Biotechnol Appl Biochem 60(5):459-481

Santoshkumar M, Veeranagouda Y, Lee K, Karegoudar TB (2011) Utilization of aliphatic nitrile by Paracoccus sp. SKG isolated from chemical waste samples. Int Biodeter Biodegr 65(1):153-159. https://doi.org/10.1016/j. ibiod.2010.10.008

Santoshkumar M, Ismailsab M, Nayak AS, Mashetty SB, Karegoudar TB (2017) Purification and characterization of amidase from Paracoccus sp. SKG: utilization of amidase-inhibited whole cells for bioconversion of acryIonitrile to acrylamide. Biocatal Agr Biotechnol 10:256-263. https://doi. org/10.1016/j.bcab.2017.04.001

Shakerkhatibi M, Ganjidoust H, Ayati B, Fatehifar E (2010) Performance of aerated submerged fixed-film bioreactor for treatment of acrylonitrilecontaining wastewater. Iran J Environ Health Sci Eng 7(4):327

Shen M, Zheng YG, Shen YC (2009a) Isolation and characterization of a novel Arthrobacter nitroguajacolicus ZJUTB06-99, capable of converting acrylonitrile to acrylic acid. Process Biochem 44(7):781-785. https://doi. org/10.1016/j.procbio.2009.03.006
Shen M, Zheng YG, Liu ZQ, Shen YC (2009b) Production of acrylic acid from acrylonitrile by immobilization of Arthrobacter nitroguajacolicus ZJUTB0699. J Microbiol Biotechn 19(6):582-587

Shen M, Liu ZQ, Zheng YG, Shen YC (2010) Enhancing endo-nitrilase production by a newly isolated Arthrobacter nitroguajacolicus ZJUTB0699 through optimization of culture medium. Biotechnol Bioproc $E$ 14(6):795-802

Shin YH, Lee HS, Lee YH, Kim J, Kim JD, Lee YW (2009) Synergetic effect of copper-plating wastewater as a catalyst for the destruction of acrylonitrile wastewater in supercritical water oxidation. J Hazard Mater 167(1):824-829. https://doi.org/10.1016/j.jhazmat.2009.01.062

Taniguchi H, Sungwallek S, Chotchuang P, Okano K, Honda K (2017) A key enzyme of the $\mathrm{NAD}(+)$ salvage pathway in Thermus thermophilus: characterization of nicotinamidase and the impact of its gene deletion at high temperatures. J Bacteriol 199(17):e00359-e00417

Tanii H, Hashimoto K (1984) Studies on the mechanism of acute toxicity of nitriles in mice. Arch Toxicol 55(1):47-54. https://doi.org/10.1007/BF003 16585

Thier R, Lewalter J, Bolt HM (2000) Species differences in acrylonitrile metabolism and toxicity between experimental animals and humans based on observations in human accidental poisonings. Arch Toxicol 74(4-5):184189. https://doi.org/10.1007/s002040000109

Wang YH, Fang XL, Cheng YP, Zhang X (2011) Manipulation of pH shift to enhance the growth and antibiotic activity of Xenorhabdus nematophila. J Biomed Biotechnol 4:672369

Wyatt JM, Knowles CJ (1995) Microbial degradation of acrylonitrile waste effluents: the degradation of effluents and condensates from the manufacture of acrylonitrile. Int Biodeter Biodegr 35(1):227-248. https://doi. org/10.1016/0964-8305(95)00031-Y

Zheng DJ, Cai WB, Wang T, Qin L, Zhang ZG, Ren XJ, Li JD, Yang ZJ (2015) Pilot-scale integrated membrane system for the treatment of acrylonitrile wastewater. Desalination 357:215-224. https://doi.org/10.1016/j.desal .2014 .11 .026

\section{Submit your manuscript to a SpringerOpen ${ }^{\circ}$ journal and benefit from:}

- Convenient online submission

- Rigorous peer review

- Open access: articles freely available online

- High visibility within the field

- Retaining the copyright to your article

Submit your next manuscript at $\boldsymbol{\nabla}$ springeropen.com 